\title{
Prevalence of Intestinal Parasites and Other Parasites among HIV/AIDS Patients with on-ART Attending Dilla Referral Hospital, Ethiopia
}

Fekadu Alemu*

Department of Biology, College of Natural and Computational Sciences, Dilla University, Ethiopia

\begin{abstract}
One of the major health problems among HIV sero-positive patients are superimposed infection due to the defect of immunity. Furthermore, intestinal parasites infection and other parasites, which are also one of the basic health problems in tropical region, are common among antiretroviral treatment patients. In this study, was aimed to assess the prevalence of intestinal parasites and other parasites among antiretroviral treatment patients in Dilla Referral Hospital. A cross sectional study design on clinical records of HIVIAIDS patients in ART clinics. Systematic simple random sampling method was used to obtain the required data. The most prevalence parasites infection were on males than females $72.00 \%$ and $28.00 \%$ in ART patients at 2011 as well as parasite infection were also shown on male ART patients with $52.00 \%$ followed by $48.00 \%$ females during 2013 . And also the most commonly infected with parasites were males with $58.33 \%$ followed by females with $41.67 \%$ at 2014 . Intestinal Parasitic infections were high among young antiretroviral treatment patients while low on children and old antiretroviral treatment patients. Therefore, the high prevalence of intestinal parasites among antiretroviral treatment patients are an evidence for the need of urgent for regular screening and de-worming of antiretroviral treatment patients.
\end{abstract}

Keywords: Antiretroviral treatment patients; Dilla Referral Hospital; E. histolytica; Human immunodeficiency virus; Parasitic infection

\section{Introduction}

Current estimates showed that at least more than one-quarter of the world's population is chronically infected with intestinal parasites and that most of these infected people live in developing countries [1-6]. Dramatic expansion of the HIV/AIDS pandemic has brought about a significant change in the fauna of intestinal parasites all over the world $[7,8]$.

Like in many other developing countries, intestinal parasites are widely distributed in Ethiopia largely due to the low level of environmental and personal hygiene, contamination of food and drinking water that results from improper disposal of human excreta [9-11]. In addition, lack of awareness of simple health promotion practices is also a contributing factor $[12,13]$. According to the Ethiopian Ministry of Health [14], more than half a million annual visits of the outpatient services of the health institutions are infected due to intestinal parasitic infections. However, this report may be an underestimate, because most of the health institutions lack appropriate diagnostic methods to detect low levels of parasite burden. In addition, some of the diagnostic methods for specific intestinal parasites, especially for the newly emerging opportunistic intestinal parasites, are not available to peripheral health institutions.

With HIV/AIDS pandemic, many intestinal parasites, previously considered being sporadic or zoonotic infections, have become opportunistic parasites causing uncontrollable life threatening diarrhoea [15-17]. As compared to developed countries, the prevalence of opportunistic intestinal parasites is expected to be higher in developing countries among HIV infected population. This is also reflected by the prevalence of opportunistic intestinal parasites in a given geographical locality among the general population $[17,18]$. HIV infection has been shown to predispose the patient to intracellular opportunistic intestinal parasites such as Cryptosporidium parvum, Isospora belli, Cyclospora cayetanensis, Enterocytozoon bieneusi and Encephalitozoon intestinalis $[15,16,19,20]$.

Almost $80 \%$ of AIDS patients die from AIDS-related infections including intestinal parasites rather than HIV infection itself [21].
Several intestinal parasites previously considered non- pathogenic or with transient pathogenic potential in immunocompetent individuals are opportunistically becoming aggressive and causing debilitating illness in HIV/AIDS patients. Most of these infections are caused by organisms that do not normally affect immunocompetent individuals [22]. The principal pathogenic intestinal parasites commonly reported as opportunistic and that cause chronic diarrhoea in HIV/AIDS patients are Cryptosporidium parvum, Isospora belli, Cyclospora cayetanensis and intestinal microsporidia (Enterocytozoon bieneusi and Encephalitozoon intestinalis).

Intestinal parasitic infections which are caused either by protozoa or helminthes or both are among the most widespread of human infections worldwide. It is estimated that as much as $60 \%$ of the World's population is infected with intestinal parasites which may play a significant role in morbidity due to intestinal infections [11] Co-infection of HIV with parasitic infections dramatically enhance progressive decline of the immune system, causing a more rapid progression to AIDS, as a result of more rapid decline of the $\mathrm{CD} 4^{+}$ T-lymphocyte counts which characteristically falls below 200 cells $/ \mathrm{ml}$ $[23,24]$ Such co-infections, generally, are the proximate cause of death of AIDS patients $[25,26]$. The rate of infection is also remarkably high in Sub-Saharan Africa, where the majority of Human Immune Deficiency Virus (HIV)/Acquired Immunodeficiency Syndrome (AIDS) cases are concentrated where factors including poverty and malnutrition could promote transmission of both infections in the region [25].

*Corresponding author: Fekadu Alemu, Department of Biology, College of Natura and Computational Sciences, Dilla University, Ethiopia, Tel: +251920839215 E-mail: fekealex@gmail.com

Received July 15, 2014; Accepted September 01, 2014; Published September 10,2014

Citation: Alemu F (2014) Prevalence of Intestinal Parasites and Other Parasites among HIVIAIDS Patients with on-ART Attending Dilla Referral Hospital, Ethiopia. J AIDS Clin Res 5: 345. doi:10.4172/2155-6113.1000345

Copyright: (c) 2014 Alemu F. This is an open-access article distributed under the terms of the Creative Commons Attribution License, which permits unrestricted use, distribution, and reproduction in any medium, provided the original author and source are credited. 
Citation: Alemu F (2014) Prevalence of Intestinal Parasites and Other Parasites among HIVIAIDS Patients with on-ART Attending Dilla Referral Hospital, Ethiopia. J AIDS Clin Res 5: 345. doi:10.4172/2155-6113.1000345

Page 2 of 5

Like in many other developing countries, intestinal parasites are widely distributed in Ethiopia largely due to the low level of environmental and personal hygiene, contamination of food and drinking water that results from improper disposal of human excreta [27]. Intestinal parasites as a major concern in most developing countries have been pronounced with the co-occurrence of malnutrition and HIV/AIDS. Opportunistic parasitic infections are a common feature in HIV/AIDS infections where almost $80 \%$ of AIDS patients die of AIDSrelated infections including intestinal parasites rather than of the HIV infection itself which usually occur late in the course of HIV infection when Cluster of Differeation (CD4) ${ }^{+} \mathrm{T}$-cell count has been severely depleted mostly below 200 cells $/ \mathrm{mm}^{3}[21,28,29]$.

In the absence of Anti Retroviral Therapy (ART) HIV/ AIDS patients in developing countries unfortunately continue to suffer the consequences of opportunistic parasites [30]. Patients enrolling into ART programmes with very low $\mathrm{CD} 4$ cell counts have heightened risk the control of these opportunistic parasitic infections in HIV-positive persons under HAART is also induced by the inhibition of the as partly protease of the parasites and by the reconstitution of the immune system of the patient $[32,33]$. Gastrointestinal infections are very common in patients with HIV infection or AIDS [34]. Human immunodeficiency virus (HIV) infection is a significant health problem with most of the cases in Asia and Africa. Similarly, intestinal parasitic infections are endemic in many developing countries of Asia and Africa due to poor sanitation, poor hygiene, and unavailability of safe drinking water. Therefore, this study was aimed to assess the prevalence of intestinal parasites and other parasites among antiretroviral treatment patients at Dilla Referral Hospital. This information will provide useful the epidemiology of those infections among HIV-infected patients in Ethiopia, thus facilitating the understanding of clinical manifestations, diagnosis and treatment management of intestinal parasitic diseases.

\section{Materials and Methods}

\section{Description of study area}

This study was conducted at Dilla Referral Hospital (DRH) which found at Dilla town, South of Addis Ababa $365 \mathrm{~km}$, in Gedeo zone. The Hospital was far from the Dilla University main campus. This study was conducted from March 2013 to June 2014 at Dilla Referral Hospital, Ethiopia.

\section{Study design}

A cross sectional study design on clinical records of HIV/AIDS patients in ART clinics. Systematic simple random sampling method was used to obtain the required data. The total sample size was $78 \mathrm{HIV}$ positive patients. of morbidity and mortality before ART [31]. There is evidence that

\section{Data collection technique}

The data collection was carried out typically by refereeing secondary data from already recorded document at Dilla Referral Hospital. The data were obtained from the data clack of antiretroviral treatment (ART) individuals at Dilla Referral Hospital.

\section{Ethical clearance}

The study protocol was reviewed and ethically approved by Dilla University ethical and clearance committee. Before data collection, an informed consent was obtained from respondents. The confidentiality of the respondents was maintained.

\section{Data analysis}

Data entry and analysis was performed using the statistical package for Social Sciences for Windows SPSS (version 16.0). For analysis of the percentage and total HIV infected individuals tested at Dilla Referral Hospital. The results were expressed graphically and as tabules.

\section{Results}

The purpose of the study was to assess the parasite disease associated on HIV patients (ART) at Dilla Referral Hospital. Consequences, 78 ART patients assessed for this study. Out of these, 46 (58.97\% were males and 32 (41.03\%) were females ART patients from 2011-2014 year at Dilla Referral Hospital.

Prevalence of intestinal parasites and other parasites among ART HIV/AIDS patients at Dilla Referral Hospital at 2011 year

The prevalence of opportunistic intestinal parasites at 2011 among ART patients at Dilla Refrral Hospital were $20.00 \%$, for both $E$. histolytica and Malaria on males at age $15-49$, Malaria with $20.00 \%$ on females at same age (Table 1).

Prevalence of intestinal parasite and other parasites amongART HIV/AIDS patients at Dilla Referral Hospital at 2012 year

The most prevalent parasitic at 2012 year among both sex were malaria $18.75 \%$ and $25.00 \%$ males and females respectively. The three intestinal parasitic were shown on ART patients during 2012 year A.lumbricoids, H.nana, T.saginata at percentage (18.75\%) (Table 2).

Prevalence of intestinal parasites and other parasites among ART HIV/AIDS patients at Dilla Referral Hospital at 2013 year

Table 3 show that toxoplasmosis were show at 2013 year among

\begin{tabular}{|c|c|c|c|c|c|c|c|}
\hline \multirow{4}{*}{ Type of parasitic infection } & \multicolumn{6}{|c|}{ Sex } & \multirow{4}{*}{ Treatment } \\
\hline & \multicolumn{3}{|c|}{ Male } & \multicolumn{3}{|c|}{ Female } & \\
\hline & \multicolumn{3}{|c|}{ Age range } & \multicolumn{3}{|c|}{ Age range } & \\
\hline & $1-14$ & $15-49$ & $>49$ & $1-14$ & $15-49$ & $>49$ & \\
\hline G. lamblia & - & $4(16.00 \%)$ & - & - & - & - & Tindazole \\
\hline E. histolytica & - & $5(20.00 \%)$ & $1(4.00 \%)$ & - & $2(8.00 \%)$ & - & Tindazole, Omeprazole \\
\hline S. stercolaris & - & $1(4.00 \%)$ & - & - & - & - & Tibendazole \\
\hline Malaria & - & $5(20.00 \%)$ & - & - & $5(20.00 \%)$ & - & Chloroquine, Ciproflaxin \\
\hline Malaria and IP & - & $2(8.00 \%)$ & - & - & - & - & Ciproflaxin, Amoxacillin \\
\hline Total & - & $17(68.00 \%)$ & $1(4.00 \%)$ & - & $7(28.00 \%)$ & - & \\
\hline
\end{tabular}

Table 1: Type of Parasitic Infection on HIV positive patients at DRH/HIV patients (ART) 2011. 


\begin{tabular}{|c|c|c|c|c|c|c|c|}
\hline \multirow{4}{*}{$\begin{array}{l}\text { Type of Parasitic } \\
\text { infection }\end{array}$} & \multicolumn{6}{|c|}{ Sex } & \multirow{4}{*}{ Treatment } \\
\hline & \multicolumn{3}{|c|}{ Male } & \multicolumn{3}{|c|}{ Female } & \\
\hline & \multicolumn{3}{|c|}{ Age range } & \multicolumn{3}{|c|}{ Age range } & \\
\hline & $1-14$ & $15-49$ & $>49$ & $1-14$ & $15-49$ & $>49$ & \\
\hline G.lamblia & - & $1(6.25 \%)$ & - & - & - & - & Cotrimoxaxole \\
\hline E.histolytica & - & $1(6.25 \%)$ & - & - & $1(6.25 \%)$ & - & Metrindazole \\
\hline S.stercolaris & - & - & $1(6.25 \%)$ & - & - & - & Cotrimoxaxole \\
\hline A.lumbricoids & $1(6.25 \%)$ & - & - & - & $1(6.25 \%)$ & - & Ameprazole \\
\hline E.coli & - & $1(6.25 \%)$ & - & - & - & - & Albendazole \\
\hline H.nana & - & - & - & - & $1(6.25 \%)$ & - & Niclosamide \\
\hline T.saginata & - & - & - & - & $1(6.25 \%)$ & - & Albendazole \\
\hline Malaria & - & $3(18.75 \%)$ & - & - & $4(25.00 \%)$ & - & Ciproflaxin \\
\hline Total & $1(6.25 \%)$ & $6(37.50 \%)$ & $1(6.25 \%)$ & - & $8(50.00 \%)$ & - & \\
\hline
\end{tabular}

Table 2. Type of Parasitic Infection on HIV positive patients at DRH/HIV patients (ART) 2012.

\begin{tabular}{|c|c|c|c|c|c|c|c|}
\hline \multirow{4}{*}{$\begin{array}{l}\text { Type of Parasitic } \\
\text { Infection }\end{array}$} & \multicolumn{6}{|c|}{ Sex } & \multirow{4}{*}{ Treatment } \\
\hline & \multirow{2}{*}{\multicolumn{3}{|c|}{$\begin{array}{c}\text { Male } \\
\text { Age range }\end{array}$}} & \multirow{2}{*}{\multicolumn{3}{|c|}{$\begin{array}{c}\text { Female } \\
\text { Age range }\end{array}$}} & \\
\hline & & & & & & & \\
\hline & $1-14$ & $15-49$ & $>49$ & $1-14$ & $15-49$ & $>49$ & \\
\hline G. lamblia & - & $4(16.00 \%)$ & - & - & $1(4.00 \%)$ & - & Metrindazole, Tindazole \\
\hline E.histolytica & - & $2(8.00 \%)$ & $1(4.00 \%)$ & - & $2(8.00 \%)$ & - & Mebendazole, ORS \\
\hline S.stercolaris & - & $3(12.00 \%)$ & - & - & - & - & Albendazole, ORS \\
\hline Toxoplasmosis & - & $1(4.00 \%)$ & - & - & $2(8.00 \%)$ & - & Cotrimoxaxole \\
\hline Hook worm & - & - & - & - & $1(4.00 \%)$ & - & Albendazole \\
\hline T. saginata & - & $1(4.00 \%)$ & - & - & - & - & Albendazole \\
\hline Malaria & - & $1(4.00 \%)$ & - & - & $6(24.00 \%)$ & - & Chloroquine, Ciproflaxine \\
\hline Total & - & $12(48.00 \%)$ & $1(4.00 \%)$ & - & $12(48.00 \%)$ & & \\
\hline
\end{tabular}

Table 3. Type of Parasitic Infection on HIV positive patients at DRH/HIV patients (ART) 2013.

males ART patients at Dilla Referral Hospital and hook worm were shown at same year among females ART patients.

\section{Prevalence of intestinal parasites and other parasites among ART HIV/AIDS patients at Dilla Referral Hospital at 2014 year}

The most commonly infected with parasites were males with $58.33 \%$ followed by females with $41.67 \%$. The elephantiasis diseases were shown on males with $8.33 \%$. The drug given to elephantiasis diseases were Doxicyclin and Albendazole.

\section{Discussion}

As results were revealed the parasitic infections among ART patients were decrease across year. The most prevalence parasites infection was among males than females $72.00 \%$ and $28.00 \%$ in ART patients respectively as indicted in Table 1 . The most commonly drug were give to the ART patients against to parasitic were as follow Tindazole, Tindazole Omeprazole, Tibendazole Chloroquine Ciproflaxin, Ciproflaxin Amoxacillin for G. lamblia, E. histolytica, S. stercolaris, Malaria and Malaria and IP respectively. Ascaris, Trichuris and Hook worm species (Ancylostoma duodenale and Necator americanus) were detected more in non-diarrheic stool samples of HIV infected, whereas the majority of (60\%-100\%) S. stercoralis, S. mansoni, E. histolytica, and G. lamblia were detected in diarrheic stool sample of HIV infected patients [35].

The most commonly drug give to the ART patients were Cotrimoxaxole, Metrindazole, Cotrimoxaxole, Ameprazole, Albendazole, Niclosamide Albendazole, Ciproflaxin against those parasites G. lamblia, E. histolytica S. stercolaris, A. lumbricoids, E. coli,
H. nana, T. saginata and Malaria respectively as indicted in Table 2. S. stercoralis, and S. mansoni was also detected more frequently (70\%75\%) in HIV infected [35]. Ascaris lumbricoides, Giardia lamblia and Trichuris trichuria (19.7\%) were the most common followed by Entamoeba histolitica (16.4\%) [36] and slightly higher prevalence of intestinal parasitosis $69.2 \%$ were found among HIV patients in Ethiopia [37].

The most prevalence parasites infections were shown on males ART patients with $52.00 \%$ followed by $48.00 \%$ females. The most commonly give drug to ART patients were Cotrimoxaxole for toxoplasmosis as indicted in Table 3. Hookworm and Ascaris lumbricoides appeared to have the highest prevalence (13.33\% and $13.33 \%)$, followed by Opisthorchis viverrini (10\%), Isospora belli (5\%), Strongyloides stercolaris (3.33\%), Cryptosporidium (3.33\%), and Microsporidium (1.67\%) infection [38]. In Zambia $80 \%$ of intestinal parasites were observed and $52.7 \%$ caused by Ascaris lumbricoides [39].

The three intestinal parasites (G. lamblia, E. histolytica Malaria) were commonly prevalence across four assessments on ART patients at Dilla Referral Hospital and also S. stercolaris commonly shown among ART patients except at 2014 year. A. lubricoids parasites were shown among ART patients at 2012 and 2014 year as indicted in Table 4. The most prevalent protozoan parasites and helminths in ART naïve patients were trophozoite of E. histolytica/dispar and A. lumbricoides with respective prevalence of $19.1 \%$ and $2.9 \%$ [40]. Slightly higher prevalence of intestinal parasitic infection (30.0\%-35.7\%) has been reported from HIV-infected individuals from Kathmandu Valley $[41,42]$. 
Citation: Alemu F (2014) Prevalence of Intestinal Parasites and Other Parasites among HIVIAIDS Patients with on-ART Attending Dilla Referral Hospital, Ethiopia. J AIDS Clin Res 5: 345. doi:10.4172/2155-6113.1000345

Page 4 of 5

\begin{tabular}{|c|c|c|c|c|c|c|c|}
\hline \multirow{4}{*}{$\begin{array}{l}\text { Type of Parasitic } \\
\text { Infection }\end{array}$} & \multicolumn{6}{|c|}{ Sex } & \multirow{4}{*}{ Treatment } \\
\hline & \multicolumn{3}{|c|}{ Male } & \multicolumn{3}{|c|}{ Female } & \\
\hline & \multicolumn{3}{|c|}{ Age range } & \multicolumn{3}{|c|}{ Age range } & \\
\hline & $1-14$ & $15-49$ & $>49$ & $1-14$ & $15-49$ & $>49$ & \\
\hline G.lamblia & - & - & $1(8.33 \%)$ & - & $1(8.33 \%)$ & - & Tindazole \\
\hline E.histolytica & $1(8.33 \%)$ & $1(8.33 \%)$ & - & - & $2(16.67 \%)$ & - & Cotrimoxaxole, ORS \\
\hline A.lubricoids & $1(8.33 \%)$ & - & - & - & - & - & Metrindazole \\
\hline T.saginata & - & - & - & - & $2(16.67 \%)$ & - & Metrindazole \\
\hline Toxoplasmosis & - & $1(8.33 \%)$ & - & - & - & - & Fansidar tablet \\
\hline Elephantiasis & - & $1(8.33 \%)$ & - & - & - & - & Doxicyclin, Albendazole \\
\hline Malaria & - & $1(8.33 \%)$ & - & - & - & - & Ciproflaxin \\
\hline Total & $2(16.67 \%)$ & $4(33.33 \%)$ & $1(8.33 \%)$ & - & $5(41.67 \%)$ & - & \\
\hline
\end{tabular}

Table 4. Type of Parasitic Infection on HIV positive patients at DRH/HIV patients (ART) 2014.

\section{Conclusion}

In the present study, high prevalence of intestinal parasites among ART patients in Dilla Referral Hospital was observed. Intestinal parasitic infections are common in HIV-infected people in Ethiopia. Based on the finding, management of ART patients by De-worming programs for intestinal parasitic disease should consider these facts for more effective treatment outcomes.

\section{Acknowledgements}

The authors would like to acknowledge Dilla University, College of Natural and Computational Sciences, Department of Biology and Dilla Referral Hospital for their support and providing information to conduct this study.

\section{References}

1. Bundy DA, Hall A, Medley GF, Savioli L (1992) Evaluating measures to control intestinal parasitic infections. World Health Stat Q 45: 168-179.

2. Saviola L, Mott Ke, Yu Sen Hai (1996) Intestinal worms. World Hlth 4: 28.

3. Chan MS (1997) The global burden of intestinal nematode infections--fifty years on. Parasitol Today 13: 438-443.

4. Albonico M, Crompton DW, Savioli L (1999) Control strategies for human intestinal nematode infections. Adv Parasitol 42: 277-341.

5. Fincham JE, Markus MB, Adams VJ (2003) Could control of soil-transmitted helminthic infection influence the HIVIAIDS pandemic. Acta Trop 86: 315-333.

6. de Silva NR, Brooker S, Hotez PJ, Montresor A, Engels D, et al. (2003) Soiltransmitted helminth infections: updating the global picture. Trends Parasitol 19: $547-551$

7. Lockwood DN, Weber JN (1989) Parasite infections in AIDS. Parasitol Today 5: 310-316.

8. Gomez Morales MA, Atzori C, Ludovisi A, Rossi P, Scaglia M, et al. (1995) Opportunistic and non-opportunistic parasites in HIV-positive and negative patients with diarrhoea in Tanzania. Trop Med Parasitol 46: 109-114.

9. World Health Organization (1981) Intestinal protozoa and helmenthic infections: Reports of a WHO Scientific Group, Geneva. Tech Rep Ser 666.

10. Teka GA (1984) Human wastes disposal in Addis Ababa: Planning and programming Bureau, Ministry of Health, Ethiopia.

11. [No authors listed] (1987) Prevention and control of intestinal parasitic infections. Report of a WHO Expert Committee. World Health Organ Tech Rep Ser 749: 1-86

12. Zein AZ (1988) Ministry of Health service in Ethiopia: A general survey in Ethiopia.

13. Kloos H, Tesfayohannes T M (1993) Intestinal parasitism. In: The Ecology of Health and Disease in Ethiopia. In Kloos H, Zein AZ (Eds.), West View Press. Oxford, 223-235.

14. Mahmoud AA (1996) Strongyloidiasis. Clin Infect Dis 23: 949-952.

15. Wittner M, Tanowitz HB, Weiss LM (1993) Parasitic infections in AIDS patients. Cryptosporidiosis, Isosporiasis, Microsporidiosis, Cyclosporiosis. Infect Dis Clin North Am 7: 569-586
16. Weiss LM, Keohane EM (1997) The uncommon gasterointestinal protozoa: Microsporidia, Blastocystis, Isospora, Dientamoeba, Balantidium. Curr Clin Top Infect Dis 17: 147-187.

17. Lindo JF, Dubon JM, Ager AL, de Gourville EM, Solo-Gabriele H, et al. (1998) Intestinal parasitic infections in human immunodeficiency virus (HIV)-positive and HIV-negative individuals in San Pedro Sula, Honduras. Am J Trop Med Hyg 58: 431-435.

18. Cimerman S, Cimerman B, Lewi DS (1999) Enteric parasites and AIDS. Sao Paulo Med J 117: 266-273.

19. Goodgame RW (1996) Understanding intestinal spore-forming protozoa: cryptosporidia, microsporidia, isospora, and cyclospora. Ann Intern Med 124 429-441.

20. Ortega RY, Sterling CR (2010) Cyclospora cayetanesis: Epidemiology and Clinical diagnosis. Clin Microbiol Rev 23: 218-234.

21. Kelly P (1998) Diarrhoea and AIDS: recent developments in the African setting Afr Health 20: 16-18.

22. Kaplan JE, Hu DJ, Holmes KK, Jaffe HW, Masur H, et al. (1996) Preventing opportunistic infections in human immunodeficiency virus-infected persons: implications for the developing world. Am J Trop Med Hyg 55: 1-11.

23. Morris A, Lundgren JD, Masur H, Walzer PD, Hanson DL, et al. (2004) Current epidemiology of Pneumocystis pneumonia. Emerg Infect Dis 10: 1713-1720.

24. Ramakrishnan K, Shenbagarathai R, Uma A, Karitha K, Rajendran R, et al. (2002) Prevalence of intestinal parasitic infections in HIVIAIDS WHO Communicable diseases chister. Severe falciparum malaria. Trans R Soc Trop Med Hyg 94: 551-590.

25. UNAIDS/WHO (2002) HIV Epidemic Update. Geneva: UNAIDS

26. Chan MS, Medley GF, Jamison D, Bundy DA (1994) The evaluation of potentia global morbidity attributable to intestinal nematode infections. Parasitology 109 : 373-387.

27. Kumie A, Ali A (2005) An overview of environmental health status in Ethiopia with particular emphasis to its organization, drinking water and sanitation: a literature survey. Ethiop J Health Dev 19: 89-103.

28. Kam KM (1994) Intestinal parasites in Hong Kong. J Trop Med Hyg 97: 117120

29. Shah UV, Purohit BC, Chandralekha D, Mapara MH (2003) Coinfection with Cryptosporidium, Isospora and S. stercoralis in a patient with AIDS--a case report. Indian J Med Microbiol 21: 137-138.

30. Maggi P, Larocca AM, Quarto M, Serio G, Brandonisio O, et al. (2000) Effect of antiretroviral therapy on cryptosporidiosis and microsporidiosis in patients infected with human immunodeficiency virus type 1. Eur $\mathrm{J}$ Clin Microbiol Infect Dis 19: 213-217

31. Lawn SD, Myer L, Orrell C, Bekker LG, Wood R (2005) Early mortality among adults accessing a community-based antiretroviral service in South Africa: implications for programme design. AIDS 19: 2141-2148.

32. Alfonso Y, Monzote L (2011) HIV Protease Inhibitors: Effect on the Opportunistic Protozoan Parasites. Open Med Chem J 5: 40-50.

33. Willemot P, Klein MB (2004) Prevention of HIV-associated opportunistic infections and diseases in the age of highly active antiretroviral therapy. Expert Rev Anti Infect Ther 2: 521-532. 
Citation: Alemu F (2014) Prevalence of Intestinal Parasites and Other Parasites among HIVIAIDS Patients with on-ART Attending Dilla Referral Hospital, Ethiopia. J AIDS Clin Res 5: 345. doi:10.4172/2155-6113.1000345

Page 5 of 5

34. Janoff EN, Smith PD (1988) Perspectives on gastrointestinal infections in AIDS. Gastroenterol Clin North Am 17: 451-463.

35. Awole M, Gebre-Selassie S, Kassa T, Kibru G (2003) Prevalence of Intestinal Parasites in HIV-Infected adult Patients in Southwestern Ethiopia. Ethiop J Health Dev 17: 71-78.

36. Sow PG, Coume M, Ndiaye PP, Boucal J C, Amousouguenou G (2012) About Intestinal Parasitic Infections in a Cohort of HIV-Infected Patients. Advances in Bioresearch 3: 32-35.

37. Mariam ZT, Abebe G, Mulu A (2008) Opportunistic and other intestinal parasitic infections in AIDS patients, HIV seropositive healthy carriers and HIV seronegative individuals in southwest Ethiopia. East Afr J Public Health 5: 169 173.

38. Wiwanitkit V (2001) Intestinal parasitic infections in Thai HIV-infected patients with different immunity status. BMC Gastroenterol 1: 3.
39. Modjarrad K, Zulu I, Redden DT, Niobuu L, Freedmen DO, et al. (2005) Prevalence and predicators of intestinal helminths infections among human immunodeficiency virus type 1 infected adult in an urban African setting. Am J trop Med Hyg 73: 777-782.

40. Missaye A, Dagnew M, Alemu A, Alemu A (2013) Prevalence of intestinal parasites and associated risk factors among HIVIAIDS patients with pre-ART and on-ART attending dessie hospital ART clinic, Northeast Ethiopia. AIDS Res Ther 10: 7.

41. Adhikari NA, Rai SK, Singh A, Dahal S, Ghimire G (2006) Intestinal parasitic infections among HIV seropositive and high risk group subjects for HIV infection in Nepal. Nepal Med Coll J 8: 166-170.

42. Sapkota D, Ghimire P, Manandhar S (2004) Enteric Parasitosis in Patients with Human Immunodeficiency Virus (HIV) Infection and Acquired Immunodeficiency Syndrome (AIDS) in Nepal. J Nepal Health Res Counc 2: 9-13. 